Criação / Música 



\section{Grupo UAKTI}

\section{ARTUR ANDRÉS RIBEIRO}

"Os instrumentos acústicos tiveram sua época de desenvolvimento,
tendo atingido um nível de perfeição muito grande. Para ilustrar,
você vê a época do Stradivarius, que até hoje não foi superada.
A partir daí, o que se faz é exatamente igual. Um violão tem
aquela forma há muito tempo; o violino, há séculos".

(Guimarães, 1983).

$\mathrm{N}$

O MUNDO pós-guerra, grandes avanços tecnológicos vem ocorrendo em praticamente todas as áreas do conhecimento. O impacto da ciência se fez sentir também na música, mediante o advento do rádio, da televisão e dos diferentes meios de suporte fonográfico. No que concerne aos instrumentos musicais, ressaltam-se o surgimento e desenvolvimento de novos instrumentos eletrônicos e sua rápida evolução, que acompanha, de certa forma, o desenvolvimento acelerado da informática. Entretanto, Marco Antônio Guimarães, fundador e líder do grupo UAKTI, nos chama a atenção, na citação acima, para uma relativa inércia na criação de instrumentos musicais acústicos tradicionais. De fato, observa-se que o surgimento de novos instrumentos para concerto encontra-se praticamente estacionado desde o final do século XIX. De lá para cá, as principais mudanças nessa área restringiram-se à melhoria dos métodos de fabricação e ao aperfeiçoamento dos princípios de funcionamento e produção do som.

Um fato comumente verificado é o hiato entre os construtores de novos instrumentos acústicos e os compositores. Esse afastamento impede o desenvolvimento de um repertório específico para ambos, o que, de certa forma, explica a tendência de acumulação das funções de construtor e compositor de novos instrumentos. No século XX, antecedendo a experiência de Marco Antônio Guimarães com o UAKTI, deve-se ressaltar o trabalho histórico de dois construtores de novos instrumentos acústicos, que conseguiram integrar suas novas fontes sonoras ao seu processo compositivo: Harry Partch (1) nos EUA e Walter Smetak (2) no Brasil.

Os trabalhos de Partch e Smetak são exceções dentro de um quadro no qual há poucos estudos sistemáticos ou consolidados sobre a criação de novos instrumentos musicais. Na Inglaterra, um projeto pioneiro denomi- 
nado Alternative Tuning Projects dirigido por Patrick Ozzard-Low (3), em parceria com a London Guildhall University, visa a criação de um Centro de Novos Instrumentos Musicais. Tal empreendimento contemplará, prioritariamente, o surgimento de novos instrumentos orquestrais no século XXI, reunindo para tanto estudiosos de diferentes áreas. Contudo, a partir da década de 80 , a construção de novos instrumentos musicais passou a congregar, cada vez mais, construtores, compositores e grupos de músicos. Desde 1986, o festival Sound Symposium, realizado bienalmente na cidade de Saint John's, Newfoundland, Canadá, dedica-se à temática da construção de novos instrumentos musicais e instalações sonoras. O simpósio reúne construtores e instrumentistas de diversos países, promovendo o intercâmbio de idéias e experiências construtivas e de performance.

\section{Marco Antônio Guimarães e o UAKTI: uma experiência musical singular}

“... somente numa família de certa tradição artesanal aconteceria o despertar para a arte de fazer instrumentos musicais. Desde pequeno, Marco Antônio viveu entre madeiras, couros e ferramentas na oficina de seu avô materno, aprendendo com ele a manejar uma plaina, um serrote, uma lixadeira. Com seus irmãos, inclusive e auxiliado por sua mãe, construía brinquedos até para os vizinhos" (Ciccacio, 1978).

A história do grupo UAKTI confunde-se com a trajetória musical de Marco Antônio Guimarães, nascido em Belo Horizonte em 10 de outubro de 1948. Sua mãe, Heloísa Fonseca Guimarães (Formiga, M.G., 1918-1978), possuía grande aptidão para atividades manuais, habilidade herdada do seu pai. Na família, era ela a responsável por grande parte de reparos caseiros como consertos em móveis, pinturas e serviços de bombeiro e eletricista. Assim como ela, Marco Antônio Guimarães também desenvolveu habilidades manuais e um espírito criativo com seu avô materno, Camilo de Assis Fonseca. Em uma entrevista à revista Manchete, Marco Antônio revelou: "Quando era criança, construía os próprios brinquedos. Meu avô tinha uma oficina e eu o admirava ali trabalhando. Por influência dele, todos os seus filhos tinham oficina na garagem. Hoje não se encontra mais marceneiro, carpinteiro" (Guimarães, Minas não trabalha em silêncio, 1989). Nos fundos da casa do avô, no bairro Santo Antônio, em Belo Horizonte, filhos e netos aprenderam o manuseio de equipamentos e ferramentas, produziam trabalhos em madeira e metal, inventos e reparos de diferentes tipos de equipamentos elétricos e mecânicos. Esta marcante influência familiar possibilitou ao jovem Marco Antônio um estreito contato com o mundo das ferramentas e materiais construtivos que, anos mais tarde, possibilitou a 
concretização de sua carreira profissional como instrumentista, compositor e criador de novos instrumentos musicais.

Marco Antônio transferiu-se para Salvador com o intuito de estudar regência e composição nos Seminários de Música da UFBA. Esta escola, pioneira no Brasil no ensino e difusão da música contemporânea, foi criada em 1954, tendo como primeiro diretor Hans Joachim Koellreutter (4) (Freiburg, Alemanha, 1915). Durante o período de quatro anos em que esteve na Bahia, Marco Antônio manteve contato com importantes músicos, mas foram os compositores Ernst Widmer (5) e Walter Smetak, quem contribuíram de forma marcante para o direcionamento de sua futura carreira musical.

Nas raízes de seu processo de criação musical, "Marco Antônio diz que foi o suíço Ernst Widmer sua maior influência. 'Na Bahia, estudei composição na escola onde Smetak ensinava, mas Widmer era o mestre de todos os compositores', lembra. 'Sua liberdade de compor me influenciou muito, tinha coragem de passear pelo atonalismo e pelo tonalismo" (Medeiros, 1994: 1). Estas influências se tornaram mais evidentes no lançamento do primeiro disco do grupo UAKTI, em 1981, ocasião em que Ilmar Carvalho fez o seguinte comentário:

"Considerando-se que este trabalho é uma amostragem da produção musical de Marco Antônio, pode-se dizer que ele faz sua música dentro dos parâmetros de uma modernidade instigante. A chamada Escola da Bahia, uma das melhores do país no campo da música contemporânea, revela para nós todos um compositor de talento, que dosa, com requinte de um estudioso inspirado, uma linha melódica breve, envolvida por procedimentos nitidamente aleatórios e de música concreta. Ele consegue, em suas partituras, extrapolar o popular, sem deixar de ser popular" (Carvalho, 1981).

Marco Antônio descreveu seus primeiros contatos com Smetak: "Em Salvador eu descobri que, no porão da Escola de Música, tinha um cara construindo instrumentos e fui lá saber o que era. Fiquei atordoado: era o violoncelista Walter Smetak, cercado por centenas de instrumentos esquisitos, extremamente coloridos. A minha vida mudou quando entrei naquele porão. Smetak, uma pessoa conhecida pela espontaneidade, a maneira direta e sincera de se dirigir às pessoas (características que lhe valeram problemas com muita gente), aceitou a presença de Marco Antônio, que passou a descer todos os dias até o porão" (Neves, 1997: 6).

Durante uma turnê do UAKTI à Espanha, Marco Antônio reconheceu a estreita relação existente entre seu trabalho e o de Smetak: "No Brasil muitas vezes consideram-me como aquele que deu continuidade ao traba- 
lho de Smetak, apesar de que atuamos, hoje, em linhas musicais bem distintas. Porém, é certo que, não fosse ele, eu não teria feito nada disto" (Guimarães, 1986). Sem dúvida alguma, a busca de novos sons, por meio da criação de novos instrumentos, foi a mais marcante influência exercida por Smetak na obra de Marco Antônio Guimarães.

Em 1978 Marco Antônio Guimarães forma, em Belo Horizonte, o grupo UAKTI, juntamente com os percussionistas Paulo Sérgio dos Santos e Décio de Souza Ramos Filho e o flautista Artur Andrés Ribeiro. O nome do grupo - UAKTI - Oficina Instrumental, deriva de uma lenda indígena dos índios Tukano do alto rio Negro:

"Uakti vivia às margens do rio Negro. Seu corpo, aberto em buracos, recebia o vento e emitia um som tão irradiante que atraia as mulheres da tribo. Os índios, enciumados, perseguiram Uakti e o mataram, enterrando seu corpo na floresta. Altas palmeiras ali cresceram: de seus caules os índios fizeram instrumentos musicais de sons suaves e melancólicos, feito o som do vento no corpo de Uakti. Ao ouvirem esse som, as mulheres estarão impuras e serão tentadas" (Antunes, 1981).

No trabalho do UAKTI, iniciado em 1978 e desenvolvido nesses 21 anos de atividade musical, ocorreram importantes parcerias, que marcaram distintas etapas da trajetória do grupo. Em 1980, foi convidado para participar do disco Sentinela (6) de Milton Nascimento, na música Peixinhos do mar, tema do folclore mineiro com arranjo de Marco Antônio Guimarães. Segundo Millarch (1981): “... o registro de Peixinhos do mar entusiasmou tanto ao Bituca [apelido de Milton Nascimento], que este os convidou para mais duas faixas: Sueño com serpientes e Um cafuné na cabeça, malandro, eu quero até de macaco." Durante turnê de lançamento do disco Sentinela (7), numa entrevista ao jornal ASI en Cronica, de Buenos Aires, Milton Nascimento, comentou sobre nossas origens comuns, assim como a íntima relação musical existente entre ambos os trabalhos. "O UAKTI e eu viemos de um mesmo lugar e essa questão da terra é para mim como um ritmo, uma melodia. Creio que é exatamente isso que nos une, por ela estamos juntos. ... Os UAKTI, no seu estilo e minha música se complementam no sentido de que queremos expressar a mesma qualidade, vinda de uma mesma origem. Dos quase 40 instrumentos que eles já fabricaram, trouxemos apenas 10 . O emprego de madeiras, bambus, pedras e água para produzir sons musicais é um dos fatores que une meu estilo ao deles" (Nascimento, 1981).

Trabalhando com Milton Nascimento, o UAKTI teve acesso ao meio fonográfico, por participações em cinco discos do compositor (8), acompanhando-o em turnês nacionais e internacionais (9) e pela assinatura do con- 
trato com a Ariola, para a gravação dos três primeiros discos solos do grupo (10), que tiveram a produção artística do próprio Milton.

O empenho em levar nossa música além das fronteiras nacionais, fez com que nos abríssemos a novas parcerias musicais. As participações do grupo nos discos Brazil, do quarteto vocal The Manhattan Transfer, em $1986 \mathrm{e}$ The Rhythm of the Saints, de Paul Simon, em 1989, possibilitaram um contato mais estreito com o ambiente artístico internacional, abrindo novas fronteiras profissionais para o grupo, o que proporcionou ao UAKTI atingir uma faixa de público ainda mais ampla. O trabalho com Paul Simon representa o elemento de transição para a segunda etapa histórica do grupo.

Essa segunda etapa foi marcada pelo encontro com o compositor Philip Glass, ocorrido em março de 1989 durante as seções de gravação com Paul Simon, que desde os primeiros contatos, reconheceu em nosso trabalho “... uma bela contribuição ao novo e experimental no mundo da música” (Glass, 1999). Incluem-se nesta segunda fase o lançamento mundial dos três primeiros CDs do UAKTI (11) pelo selo Point-Music de Nova Iorque; apresentações em conjunto com outros artistas, como o baterista Stewart Copeland e The Rhythmatists (1994); realização de diversas turnês de concertos e workshops, pelos EUA, Europa e Brasil; intensificação das atividades didáticas do grupo (12) e elaboração de trilhas de balé (13), especialmente compostas e gravadas para o Grupo Corpo.

Nesse período, o trabalho musical do UAKTI foi reconhecido, também, em âmbito nacional, pela conquista de duas importantes premiações: Prêmio Ministério da Cultura - melhor grupo de música instrumental de 1996 e Prêmio Santista-melhor grupo de música popular brasileira de 1997. Esse período caracterizou-se ainda pela intensificação dos trabalhos do UAKTI em nosso país: as primeiras trilhas sonoras para longa-metragens: Kenoma, de Eliane Café; Outra Estórias, de Pedro Bial; Lavoura Arcaica, de Luís Fernando Carvalho; concertos e workshops em diversas cidades brasileiras e uma turnê nacional do show Atracatraca, em parceria com Naná Vasconcelos.

O recente lançamento mundial do CD Águas da Amazônia (14), em parceria com o compositor Philip Glass, marca o início de uma nova etapa de realizações do grupo. Reconhecido internacionalmente como um dos mais importantes compositores da atualidade, Philip Glass representa, hoje, uma das vertentes da nova música do século XXI. A oportunidade de realizar um trabalho sobre oito temas inéditos do compositor, além de um arranjo, na forma de tema com variações, da música Metamorphosis I, representa para o grupo o início de uma nova etapa de trabalho. No texto de apresentação do CD, Philip Glass escreveu: 
“Anos atrás, quando encontrei o UAKTI por primeira vez, vi em sua música e performance algo único e uma bela contribuição ao novo e experimental no mundo da música. Me tornei, desde então, amigo de todos eles; especialmente tornei-me um admirador da extraordinária capacidade de Marco Antônio no que diz respeito ao ouvir e compor. Fiquei muito feliz, quando, anos mais tarde, eles me propuseram um trabalho em parceria. Seria a partitura de um balé, composto para a companhia de dança Grupo Corpo, de sua cidade, Belo Horizonte. Este CD representa uma verdadeira integração entre a minha música e a sensibilidade deles. Para mim, é um deleite e um enorme prazer ouvir o resultado final” (Glass, 1999).

\section{Como surge um novo instrumento?}

“Como se dá o início da criação de um novo instrumento?” Esta pergunta, que nos é feita, freqüentemente, por repórteres de diferentes países, foi exatamente uma das questões elaboradas por Galilea (1986) e que obteve de Marco Antônio Guimarães a seguinte resposta:

"Há vários caminhos diferentes. As vezes é a busca de um material. De repente surge a idéia de pesquisar um determinado material. Então investigo aquilo um certo tempo para verificar as possibilidades de sua utilização em um novo instrumento, que extensão seria possível explorar ... muitas vezes não sei qual vai ser o resultado. Em outros casos é uma necessidade musical. O grupo necessita de um determinado tipo de instrumento. Foi este o caso do Planetário. Faltava um instrumento grave para as cordas. E outras vezes parto da idéia do mecanismo de emissão sonora. Por exemplo um instrumento de teclado, de percussão, que possa ser tocado com arco, com coisas que caiam em cima da tecla, a água que cai... O sistema de produção do som é a idéia base. Há também outros caminhos. Como basear-se em um instrumento tradicional e proceder alguma modificação".

As respostas dadas por Marco Antônio Guimarães, durante todos esses anos, indicam que o impulso gerador do seu trabalho de construção de novos instrumentos origina-se a partir de um dos sete diferentes fatores básicos:

- a descoberta e pesquisa sonora de novos materiais;

- a pesquisa feita a partir de uma necessidade musical do compositor ou do grupo;

- a pesquisa feita a partir de um resultado sonoro pré-selecionado, mediante a observação de fenômenos físicos naturais; 
- a pesquisa feita a partir do mecanismo básico de emissão sonora;

- a projeção de seu desenho ou planta;

- a pesquisa a partir da modificação ou releitura dos instrumentos tradicionais e de suas técnicas de performance;

- a pesquisa feita a partir da reciclagem de materiais do cotidiano.

No primeiro caso, que é o mais freqüente, parte-se da fonte sonora e do estudo de suas qualidades, potencialidades e limitações. Guimarães (1999) afirmou que "... o processo de construção sempre foi muito assim, de sair experimentando o material que estava a minha volta, e se fosse o caso, sair procurando". A partir da escolha de um determinado material, verifica-se o seu potencial sonoro, a extensão possível de suas freqüências, sua resistência e a viabilidade quanto ao seu dimensionamento (instrumentos de grandes dimensões inviabilizam o seu transporte, principalmente por via aérea). Dáse início então, à busca de soluções que otimizem seu aproveitamento, sendo necessário, também, a busca de soluções para problemas tais como neutralização de ruídos indesejáveis, fadiga de material e dificuldades para a amplificação do som. Sobre isso Guimarães (1984) comentou:

"Quando se lida com materiais que nunca foram usados em instrumentos musicais, não se têm parâmetros nem referências; é preciso experimentar até atingir o resultado procurado ... De repente, os timbres graves soam bem mas os agudos não, ou vice versa. Então, você tem que encurtar ou esticar um pouco mais a corda, ou ainda fazer modificações na caixa, até obter uma boa extensão de afinação".

É neste primeiro tipo de procedimento de inicialização, que se enquadram a maior parte dos instrumentos do UAKTI.

No segundo caso, já não é o material quem está indicando o caminho a ser percorrido, mas uma necessidade musical específica que o compositor ou o grupo tenha num dado momento. O que também diferencia esse segundo procedimento de inicialização do anterior, é a presença de fatores que restringem a pesquisa, principalmente no que concerne ao tipo de material a ser utilizado. Para exemplificar, suponhamos que o compositor ou o grupo, necessite de um instrumento grave, para cumprir a função de baixo. Neste caso, a utilização de materiais que produzam somente freqüências médias e agudas já estaria naturalmente descartada dessa pesquisa.

No terceiro caso, parte-se de um certo ideal sonoro, um determinado tipo de som que se queira trabalhar. Aqui, os materiais a serem utilizados na cons- 
trução do novo instrumento estão submetidos a uma necessidade maior, no caso, a obtenção do objetivo proposto - a manipulação de um determinado som. Um exemplo claro da utilização desse terceiro parâmetro de construção é o Aqualung (15), quando Marco Antônio Guimarães buscou construir um instrumento musical, partindo do som resultante de um fenômeno físico natural, que decorre do ato de se encher uma garrafa com água. A partir do referencial desse som, que vai naturalmente do grave ao agudo, o construtor empreendeu diversas pesquisas visando à manipulação desta matéria sonora específica. Na construção do instrumento, Marco Antônio Guimarães utilizou basicamente materiais do cotidiano, como madeira, dois tubos de PVC de diâmetros diferenciados, um galão plástico para 20 litros, uma garrafa plástica de refrigerante de dois litros, uma pequena torneira de metal, uma peça de seringa descartável, mangueira cirúrgica de látex, chapas acrílicas e dois níveis de pedreiro. Todos esses elementos, devidamente combinados, resultaram na criação de um instrumento extremamente inovador, de grande capacidade expressiva e que testemunha a extraordinária capacidade inventiva de seu criador.

Para exemplificar melhor a intensidade do processo criativo de Marco Antônio Guimarães e o alto grau de envolvimento que ele dedica à pesquisa, lembro-me de um fato ocorrido no período da construção desse instrumento. Estávamos na casa de minha mãe, a artista plástica mineira Maria Helena Andrés. Situada no Condomínio Retiro das Pedras, próximo à cidade de Belo Horizonte, sua casa possui um telhado em concreto armado, na forma hexagonal e que, em todo o contorno de seu perímetro, não possui calhas para a canalização de água pluvial. Enquanto lá estávamos, começou a chover intensamente. Devido ao declive natural do terreno, os diversos filetes de água que caíam, produziam freqüências distintas, ao tocar a água na superfície do solo, fruto das diferentes distâncias entre o beiral do telhado e o chão. Naquele momento, fui mais uma vez surpreendido por uma estranha e genial idéia, de Marco Antônio Guimarães: a de se construir um Órgão de Água. Para funcionar, esse instrumento necessitaria de um grande reservatório de água, conectado a uma seqüência de tubos de PVC dispostos em escala. Por meio de um sistema de teclado, o performer acionaria o mecanismo de controle de cada um dos filetes de água, de diferentes comprimentos, devido à disposição dos tubos em escala, possibilitando a execução de acordes e de desenhos melódicos. Este instrumento teria, ainda, possibilidades dinâmicas na medida do aumento ou diminuição do volume e pressão da água. Quando de nossa entrevista, perguntei a Marco Antônio Guimarães sobre suas lembranças desse período, o que possibilitou o resgate de outras idéias associadas à questão da utilização da água como fonte sonora: 
“Eu lembro da conversa, sim, não me lembro onde foi, não é? Porque, quando a oficina do UAKTI era na rua Santa Rita Durão [no bairro Funcionários, em Belo Horizonte], na parte detrás da casa, que era de dois andares, não tinha calha, então, caía água de lá de cima com uma certa força. Eu cheguei a fazer uma série de experimentos, lá, na época de chuva, a maior parte deles com percussão, utilizando uma grande quantidade de panelas viradas ao contrário ... E deixava tocando, lá ... e com a chuva mais forte, o som fica mais contínuo. Mas quando a chuva ia parando, ela começava a variar o ritmo das gotas, era muito interessante, tanto o som como ritmo que criava ... Cheguei a imaginar uma série de instrumentos para serem instalados num parque e vários deles utilizariam o funcionamento com água. Me lembro de um deles, que utilizava o princípio do monjolo, por exemplo. Uma parte do projeto, seria uma sala cujo telhado seria feito de tal forma que sua inclinação coletasse a água da chuva e a canalizasse para diversos tubos. Teria também, ramificações e cada uma iria para um lado. Então, parte da água iria para um lado que gotejava em cima de panelas, outra parte encheria o monjolo, produzindo o seu movimento de subida e caída. E, outra parte iria para o Órgão de Água. Foi nessa época, quando eu fiz o Aqualung ... Eh, o Aqualung é interessante, porque eu experimentei o sistema do tubo, com a água caindo na água, e o tubo móvel. E resolvi fazer um instrumento. E eu estava com paciência, na época, então eu fiz um instrumento supercaprichado, com 'cinqüenta' mãos de verniz, porque o instrumento iria lidar com água, dois níveis de pedreiro, para o filete de água cair certo. 'Uma dúzia' de mãos de verniz marítimo. E na mesma hora em que eu fiz o Aqualung, 'mono' (risos) ... dava para imaginar ele multiplicado, como um órgão e tal. Cheguei até a solucionar algumas questões, fiz vários desenhos. Porque um dos problemas que você tem que solucionar é a altura com que cai o filete de água, porque tem sempre um atraso. Ele cai e quando chega na água é que vem o som. Se você colocar cada torneirinha na altura de cada um dos tubo, o tubo mais grave vai demorar mais. Então, o registro grave vai ter um atraso maior do que o agudo. Conseqüentemente, todos têm que ficar na mesma altura. O filete do grave, por exemplo, tem que percorrer no ar uma distância muito grande para cair lá em baixo. Tem que ter, também, uma grande precisão, pois se tiver vento, por exemplo, já complica. E, além disso, é um som extremamente leve, que você terá que amplificar, com microfones em cada um dos tubos. Quanto ao sistema de teclado, eu cheguei a pensar em vários, para que o instrumentista, a partir do teclado abrisse as válvulas, lá em cima. Tem várias possibilidades. Mas esse que você está falando, seria um instrumento para se colocar numa casa, não é? Então, quando chovesse, ele tocaria uma música, tocaria acordes, daria até para calcular pela própria calha, se fosse um tipo de calha especial, que gotejasse mais ou menos, em lugares diferentes" (Guimarães, 1999). 
Pela simplicidade da idéia e pela possibilidade de antever o seu resultado, a partir daquela massa disforme de clusters de sons de água que a chuva intensa produzia, guardo a nítida lembrança do sentimento que tive naquele momento: o privilégio de estar na presença de um artista, possuidor de uma inventividade criativa realmente singular. A meu ver, não é por acaso que “... Philip Glass, em entrevista a um jornal carioca, disse que os três compositores que mais têm ouvido ultimamente são 'Debussy, Arvo Päart e Marco Antônio Guimarães"” (Medeiros, 1994).

Devido às dificuldades técnicas e operacionais, como dimensionamento, custo e local para instalação, o Órgão de Água nunca chegou a ser construído. Porém, permaneceu em minha memória, como uma real possibilidade de expansão das três tradicionais famílias de instrumentos musicais: cordas, sopros e percussão.

O quarto fator que viabiliza o surgimento de um novo instrumento, é determinado por meio de uma pesquisa que se inicia a partir do mecanismo básico de emissão sonora. Nestes casos, o mecanismo de emissão do som se torna o ponto de partida para a idealização do projeto. Os elementos preponderantes já não são mais o material a ser utilizado como fonte sonora, uma necessidade musical do grupo ou um fenômeno físico-sonoro, mas o mecanismo que irá produzir o som.

“Os primeiros instrumentos eram exclusivamente acústicos, com uma sonoridade singular e incrivelmente bela, apesar de insólitos e inesperados. Depois, Marco passou a usar novos recursos na criação dos instrumentos. São idéias que só funcionam com mecanismos elétricos. O resultado é impressionante. A idéia é também usar o potencial elétrico, que possibilita, como vantagem prática, construir um instrumento portátil. Se fossem acústicos teriam de ser enormes. Ao contrário dos aparelhos eletrônicos que criam o som, nos elétricos o som existe mesmo. O captador lê o som e o amplifica ..." (Finatti, 1990).

No trabalho de Marco Antônio Guimarães, é também comum nos depararmos com a utilização de motores como agentes mecânicos de emissão sonora. No ano de 1996, quando Marco Antônio Guimarães compunha o seu último trabalho em parceria com o Grupo Corpo, o ainda inédito Música do acaso, ele construiu um instrumento denominado Nastaré (16) que, para sua performance, dispensa a participação do instrumentista.

"Com um motor de gravador velho no vértice de um tripé, ele construiu uma espécie de caixa de música. O motor gira, fazendo rodar um tubo de borracha ao qual está presa uma baqueta. A baqueta bate numa série de 
tubos e a música sai, aleatória, hipnótica. Parece uma brincadeira. 'Mas é uma brincadeira', diz Marco Antônio Guimarães. ... Marco Antônio fez o 'brinquedo' durante uma série de pesquisas sobre a música do acaso de que falava o compositor americano John Cage, em busca de composições que não tivessem um padrão" (Medeiros, 1994).

O que torna este instrumento especialmente interessante, é sua capacidade de improvisar rítmica e melodicamente, mediante o movimento irregular da baqueta, que, ao ser girada, percute, de forma não repetitiva, os doze tubos de alumínio que constituem as fontes sonoras do instrumento.

O quinto fator de geração de um novo instrumento, ocorre por meio da projeção de seu desenho ou planta. Questionado sobre quais dos seus instrumentos teriam sido criados a partir de um desenho ou planta, Guimarães (1999) respondeu:

"De vários deles eu fiz um esboço, mas quase todos mudaram muito durante o processo de criação, porque, às vezes eu precisava de um material, uma peça de uma determinada forma e, de repente, eu parava naquilo. Dali, eu encontrava uma peça semelhante que podia substituir e acabava mudando a forma. ... É muito difícil desenhar e partir para fazer. ... O único que foi feito exatamente como o desenho foi o Peixe, porque também era muito simples, mas ele tinha que ter o braço afastado da corda, por causa do movimento da baqueta, foi o que mais próximo ficou do desenho."

Conforme esse relato de Marco Antônio Guimarães, dentre os vários desenhos de novos instrumentos por ele elaborados, somente o Peixe (17), um instrumento de cordas duplas com cabaça, seguiu exatamente o projeto e a forma prevista. Em todas as outras experiências, nas quais o desenho serviu como ponto de partida para o trabalho de construção, houve, no transcurso de sua realização, modificações significativas com relação ao projeto original.

A sexta possibilidade, baseia-se na pesquisa a partir da modificação ou releitura dos instrumentos tradicionais e de suas técnicas de performance. De acordo com uma matéria jornalística publicada no jornal Estado de Minas, em 1996, quando do show de lançamento do CD 21, “... a história do UAKTI tem um forte embasamento no interesse dos integrantes de romper com os preconceitos contra instrumentos considerados 'menores' (como a cuíca) e desmistificar o status de outros (como o piano)" (Estado de Minas, 1996). Conforme dito anteriormente, a possibilidade de “... basear-se em um instrumento tradicional e proceder alguma modificação" (Guimarães, 1986), gerou algumas experiências interessantes. 
Já a pesquisa de novas técnicas de performance requer do instrumentista o desenvolvimento de uma capacidade de se relacionar com os instrumentos musicais de uma forma nova, desprovida de preconceitos. Segundo Guimarães (1996), “... desde o início da pesquisa muitos preconceitos foram quebrados. No UAKTI os instrumentos ganharam diferentes tipos de forma e todos foram valorizados da mesma maneira." Lidar com novos instrumentos, a partir de uma postura mais livre e aberta, possibilitou aos performers do UAKTI a relacionarem-se, também, de forma mais justa, com os instrumentos ditos tradicionais.

O sétimo e último ponto de partida para a construção de um novo instrumento acústico, que pudemos identificar, provém da pesquisa feita a partir da reciclagem de materiais do cotidiano e de partes de instrumentos musicais. Este trabalho de reciclagem, foi iniciado a partir da construção da Roda, instrumento construído no final da década de 70, quando o compositor Marco Antônio Pena Araújo (1948-1985) teve sua casa totalmente incendiada. Uma das poucas coisas que, estando no interior de sua residência, escapou à ação do fogo, foi o mecanismo interno dos martelos do piano. Fomos então presenteados com tal objeto, que Marco Antônio Guimarães aproveitou para utilizar na construção desse instrumento de cordas.

O Taquará é outro exemplo de reciclagem de parte de um instrumento musical. Certa vez, um amigo que possuía um Órgão de boca, instrumento oriental de origem chinesa, nos procurou. $\mathrm{O}$ instrumento havia se danificado e já não funcionava mais. Fomos presenteados, então, com alguns dos bambus que outrora constituíam o instrumento oriental. Estes possuem palhetas metálicas em suas paredes externas, que produzem sons quando soprados. Marco Antônio Guimarães reaproveitou-os, de forma inteiramente nova, ao fixar, em cada uma de suas extremidades abertas, uma pêra de borracha, normalmente utilizada em buzinas de bicicleta. Ao pressioná-la com uma das mãos, é possível executar diferentes ritmos, com extrema rapidez e regularidade.

Podemos notar que a utilização de materiais reciclados gera, algumas vezes, restrições à longevidade e conseqüente consolidação de um novo instrumento, principalmente no caso de o instrumento demandar a substituição periódica de algum desses componentes reciclados. Este problema ocorreu com o instrumento Latinhas, cuja construção se baseava na utilização percussiva de tampas metálicas dos vidros de maionese, de café solúvel e de compotas, que eram, até o final dos anos 80 , utilizadas pelas indústrias do ramo. No decorrer da década de 90, houve modificações substanciais no procedimento de embalagem desses produtos, com a utilização predomi- 
nante de material plástico, tanto na fabricação dos potes quanto de suas tampas. Com isso, a utilização musical desse instrumento teve de ser interrompida, pois suas tampas metálicas demandavam substituição periódica, devido ao desgaste natural de sua utilização na forma percussiva.

"Uma novidade de 21 é um texto de apresentação escrito pelo sociólogo Herbert de Souza, o Betinho, que se encantou com o UAKTI após assistir a uma apresentação do grupo no Rio. . . O encontro entre o UAKTI e Betinho, no começo deste ano, foi um momento particularmente interessante para os quase 20 anos de carreira da oficina. O sociólogo se encantou com um espetáculo no Heineken Festival e entrou em contato com o grupo. Quando Herbert de Souza viajou até a capital de Minas, ele foi recepcionado com uma apresentação particular na oficina do grupo no bairro Serra. Da visita surgiu a idéia de fazer um texto para abrir 21, onde Betinho demonstra o imenso impacto que sentiu ao conhecer o grupo mineiro. O texto deixou os músicos muito satisfeitos. 'É uma visão muito particular dele, ao mesmo tempo mineira e cósmica, foi um privilégio para nós' diz Artur. 'É simpático e bonito. Ele fala de coisas que ficou imaginando ao ouvir o disco', elogia Guimarães” (Lana, 1996).

\section{UAKTI}

$M$ ETADE DEUs. METADE DIABO. Na exata e mineira medida, como é a vida. Num único espaço e tempo estão juntos porque necessariamente diferentes e necessários um ao outro: não há vida sem morte, prazer sem dor, sim sem não, princípio sem fim, agudo sem grave, veloz sem lento, grande sem pequeno. Deus sem Diabo.

Tudo é metade e o contrário da outra parte, diferente para fazer a unidade do que é contrário. Foi escutando o UAKTI que aprendi o que sempre me recusei a aceitar: que todo diferente é, no fundo, parte de um mesmo igual. 'Yin' e 'Yang'. Deus e o Diabo, num empate aceito pelos dois, eis o mistério. Negado em todas as partes, mas não em Minas Gerais, onde o empate é reconhecido no se, no talvez, no não sei se sim ou se não, na indefinição que define todo o saber e fazer. Em Minas o normal é o empate. O desempate é puramente provisório.

Minas Gerais, um estado particular e único do Brasil. Central, no meio de tudo, com extremos, mas sem se definir. Um lugar onde a vida e a morte conversam todo o tempo sem se despedir. Terra de Milton Nascimento, de João Guimarães Rosa e do UAKTI, sem mar, mas com imensidão. Terra onde a liberdade foi esquartejada na Inconfidência Mineira de Tiradentes no século 18, mas permanece de corpo inteiro. O lugar onde a liberdade dura ainda que tardia. Enfim, o mistério.

Foi lá que nasceu o UAKTI e só poderia ser. Quatro anjos vertidos em demônios entraram na música e fizeram uma grande filosofia pela via das notas, do estalo, do contraste, do espanto, da doçura e da violência sem limites do som que ultrapassa todas as barreiras. Transcenderam o tempo e o espaço, rescreveram Einstein por cima de toda relatividade. Foram tão acima de tudo que tiveram que inventar até os instrumentos. E inventaram como Deus fez no começo e o Diabo ajudou. Deus inventou a humanidade, o UAKTI inventou o instrumento da música.

Não se pode entender o UAKTI sem se levar esse choque do totalmente Deus e totalmente Diabo, uma coisa que todo mineiro entende e aqueles que podem praticam.

O fim do mundo está no começo e o UAKTI é esse Verbo.

Herbert de Sousa [Betinho] foi sociólogo. 
Notas

1 Harry Partch, nasceu na cidade de Oakland, Califórnia, EUA, em 24 de junho 1901, vindo a falecer em San Diego, Califórnia, em 3 de setembro de 1974. Harry Partch idealizou e construiu uma série de instrumentos, em sua maioria de cordas e percussão, para os quais definiu novas escalas microtonais.

2 Walter Smetak, nascido em 1913, de origem suíça, era violoncelista, compositor e construtor de instrumentos não-tradicionais. Emigrou para o Brasil, em 1937, onde trabalhou como violoncelista das mais importantes orquestras e institutos de artes, do Rio Grande do Sul, do Rio de Janeiro e de São Paulo onde viveu até meados da década de 50. Finalmente, mudou-se para Salvador, no ano de 1957, a convite do professor Hans Joachim Koellreutter, para lecionar nos Seminários de Música da UFBA. A partir de 1958, paralelamente à sua atividade como violoncelista e professor, começou a se dedicar, com maior intensidade, à construção de novos instrumentos. Movido pela idéia de que "uma nova humanidade requer uma nova música, fazendo-se necessária a construção de novos instrumentos musicais", Smetak construiu, durante seus últimos 26 anos de vida (faleceu em 1984), 150 novos instrumentos musicais, utilizando materiais os mais diversos, como cabaça, bambu, madeira, tubos de PVC, mangueiras plásticas etc.

3 Patrick Ozzard-Low, pianista, compositor e filósofo, nasceu na Inglaterra em 1958. Estudou composição com Bill Hopkins, discípulo de Jean Barraqué. Durante o ano de 1998, subvencionado pelo programa Churchill Fellow, viajou pelos EUA, Brasil e Europa, coletando informações para o seu livro 21st century orchestral instruments.

4 H.J. Koellreutter, é compositor, regente e flautista. Emigrou para o Brasil em 1937, onde rapidamente se tornou uma das mais importantes figuras do cenário artístico do país nas áreas de criação, ensino e divulgação musical. Fundou importantes movimentos musicais como o Música Viva (1938-39), os Cursos Internacionais de Música de Teresópolis (1950), a Escola Livre de Música de São Paulo (1952) e os Seminários de Música da UFBA (1954), dos quais esteve à frente durante nove anos, no cargo de diretor. Em Salvador, coube a ele a missão de contratar músicos e professores, tanto do país quanto do exterior, com o objetivo de criar um novo núcleo de ensino musical no Brasil.

5 Ernst Widmer foi compositor, regente, pianista e professor, nascido a 25 de abril de 1927, em Aarau, Suíça, local onde veio a falecer, em 3 de janeiro de 1990. Segundo Nogueira (1997: 21): "Brasileiro por opção pessoal, Widmer foi um dos construtores da música brasileira contemporânea, à frente dos festivais e cursos de música nova, apresentações de jovens compositores e concursos de composição, que marcaram a cultura e a educação musical da Bahia e do Brasil neste século".

6 Rio de Janeiro, Ariola, 1980. 
7 A turnê percorreu sete cidades brasileiras: Belo Horizonte, Rio de Janeiro, Fortaleza, Natal, Recife, São Paulo, Ribeirão Preto, além de três apresentações na capital da Argentina, Buenos Aires.

8 Além do disco Sentinela, o UAKTI participou dos seguintes trabalhos de Milton Nascimento: Caçador de mim (Ariola-1981), nas faixas: De magia, de dança e pés e Coração civil; Ânima (Ariola-1982), na faixa Ânima; Encontros e despedidas (Barclay-1985), nas faixas: Lágrima do Sule Portal da cor; Yauaretê (CBS1987) nas faixas Dança dos meninos e Carta à República.

9 Durante o mês de julho do ano de 1986, a convite do Ministério da Cultura Espanhol, o UAKTI participou de uma turnê de oito shows pela Espanha, ao lado de Milton Nascimento e da cantora catalã Maria Del Mar Bonet.

10 Uakti-Oficina Instrumental, Ariola (1981), Uakti II, Ariola-Barclay (1982) e Tudo e todas as coisas, PolyGram (1984).

11 Mapa (1992), I Ching (1994) e Trilobyte (1997), Nova Iorque, Point-Music.

12 UAKTI - Programa Artista Visitante na UFMG, 1994-1995.

13 A Lenda (1989), 21 (1992) e Sete ou oito peças para um balé(1993).

14 Nova Iorque, Point-Music, 1999.

15 Vide Catálogo Descritivo dos Instrumentos do UAKTI, cap. III.

16 Id. Ibid.

17 Vide capítulo 3, instrumentos de cordas.

\section{Referências bibliográficas}

ANTUNES, Murilo. Uakti-Oficina Instrumental. Rio de Janeiro, PolyGram, 1981. Versão da lenda de Uakti.

ASI en cronica. Milton Nascimento, cada vez mas brasileño. Buenos Aires, ASI en Cronica, p. 15, 5 abr. 1981.

CARVALHO, Ilmar. A nova música brasileira feita com tubos de PVC. Joinville, Cia. Hansen Industrial, dezembro 1981.

CICCACIO, Ana Maria. A arte de criar instrumentos. O Estado de São Paulo, l fev. 1978.

ESTADO DE MINAS. Uakti premiado. Belo Horizonte, Estado de Minas, E. Mais, p. 3, 5 nov. 1996.

Novas propostas do Uakti. Belo Horizonte, O Estado de Minas, Espetáculo, 1 dez. 1996.

FINATTI, Humberto. Grupo Oficina - Uakti pesquisa e fabrica seus próprios instrumentos. São Paulo, ISTOÉ Senhor, 3 out. 1990. 
GALILEA, Carlos. Uakti: La magia de la selva. Barcelona, revista La Luna, p. 2829, ago. 1986.

GLASS, Philip. Águas da Amazônia. Nova Iorque, Point-Music, 1999. Encarte.

GUIMARÃES, Marco Antônio. Oficina Instrumental Uakti. O design espontâneo. Entrevista a Marcelo de Resende. Belo Horizonte, revista Pampulha, p. 12-15, dez. 1983.

Uma fábrica de sons. Entrevista a Raquel Faria. São Paulo, revista Visão, p. 66-68, 12 nov. 1984.

Uakti: La magia de la selva. Entrevista a Carlos Galilea. Barcelona, revista La Luna, p. 28-29, ago. 1986.

. Minas não trabalha em silêncio. Entrevista a Ricardo Rodrigues. Rio de Janeiro, Manchete, p. 74-77, mar. 1989.

Novas propostas do Uakti. Belo Horizonte, O Estado de Minas, Espetáculo, 1 dez. 1996.

Uakti promove aula/show no Instituto Itaú. Entrevista a Jotabê Medeiros. O Estado de S. Paulo, caderno 2, p.D2, 11 jul.1997a.

Villa-Lobos na batida de uma nota só. Entrevista a Vitória Neves, Belo Horizonte, O Tempo, Magazine, p. 6, 11 maio 19976.

Entrevista de Marco Antônio Guimarães ao autor. Belo Horizonte, 15 set. 1999. Vide anexos.

LANA, Fabiano. Oficina sonora em formato de CD. Rio de Janeiro, Jornal do Brasil, Caderno B, p. 2, 7 dez. 1996.

MEDEIROS, Jotabê. Uakti promove aula/show no Instituto Itaú. O Estado de $S$. Paulo, Caderno 2, p. D2, 11 jul. 1997.

MILLARCH, Aramis. A água, o vento e a natureza na música de Smetak, Uakti e Falcão. Curitiba, Estado do Paraná, 1981.

NASCIMENTO, Milton. Milton Nascimento, cada vez mas brasileño. Buenos Aires, ASI en Cronica, p. 15, 5 abr. 1981.

NEVES, Vitória. Villa-Lobos na batida de uma nota só. Belo Horizonte, O Tempo, Magazine, p. 6, 11 maio 1997.

OHTAKE R. Instrumentos musicais brasileiros. São Paulo, Rhodia S.A., 1988, p.194.

OZZARD-LOW, Patrick. $21^{\text {st }}$ Osquestral Instruments. Londres: http://www.c21orch-instrs.demon.co.uk, 1997.

SOUSA, Herbert de. 21. São Paulo, Brasil: Paradoxx, 1997. Encarte do CD.

Artur Andrés Ribeiro, músico, é integrante do Grupo UAKTI, e professsor da Escola de Música da UFMG. Este texto é um capítulo da tese UAKTI: a construção de novos instrumentos musicais acústicos, cuja 'defesa direta' será feita pelo autor na UFMG. 


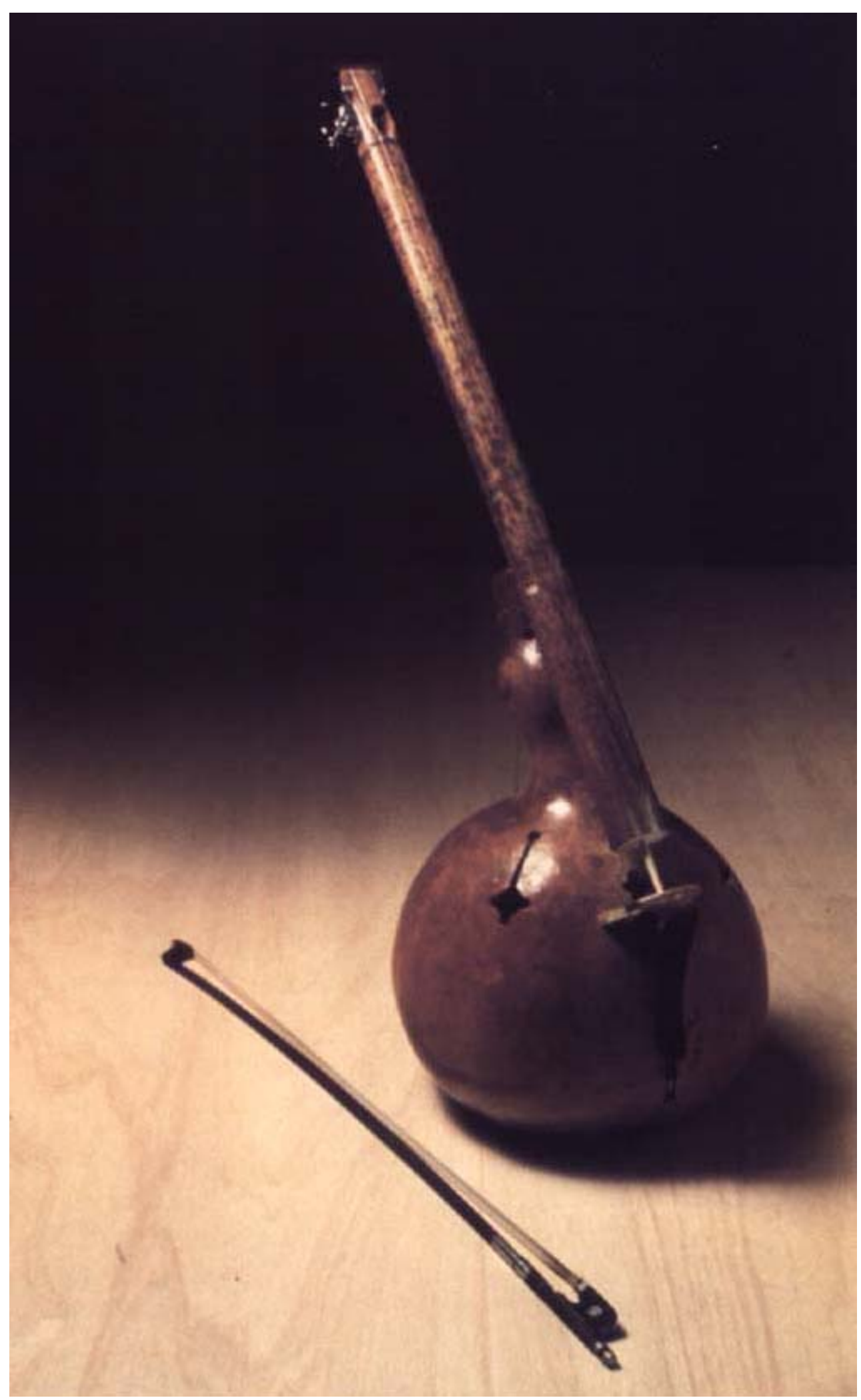

(C) 1994 Cristiano Quintino - CHORI SMETANO 


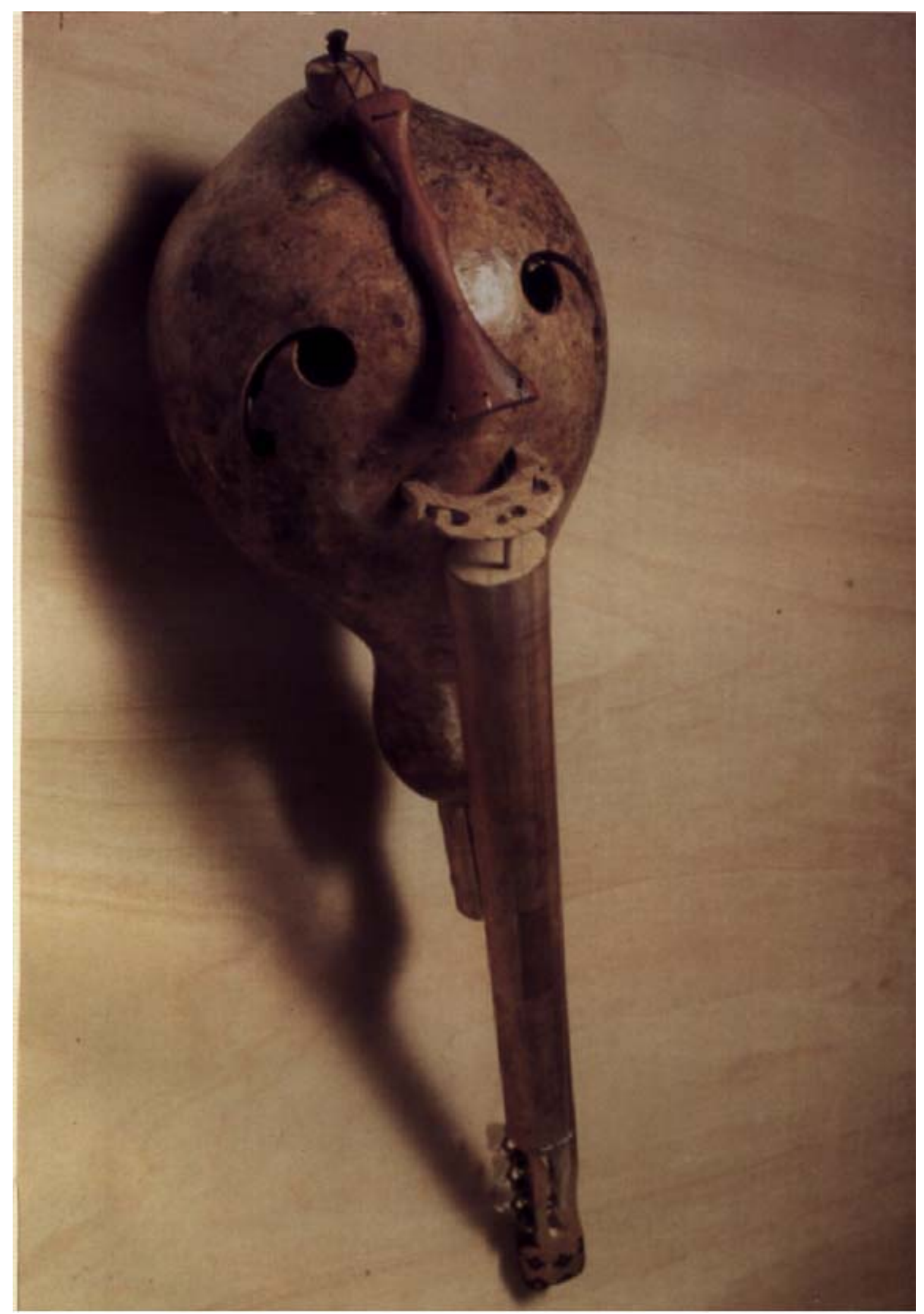

(C) 1994 Cristiano Quintino - CHORINHO 


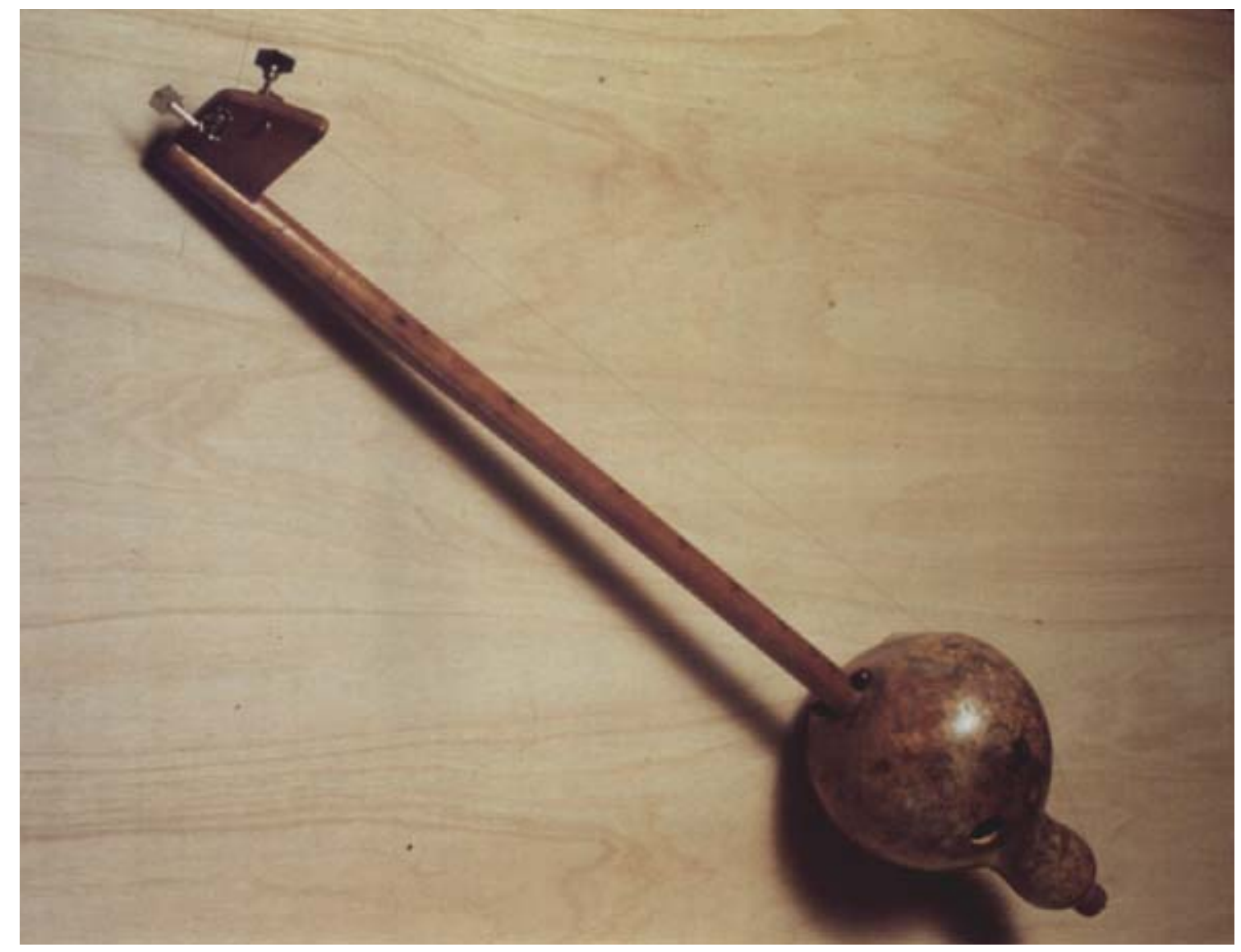

(C) 1994 Cristiano Quintino - PEIXE

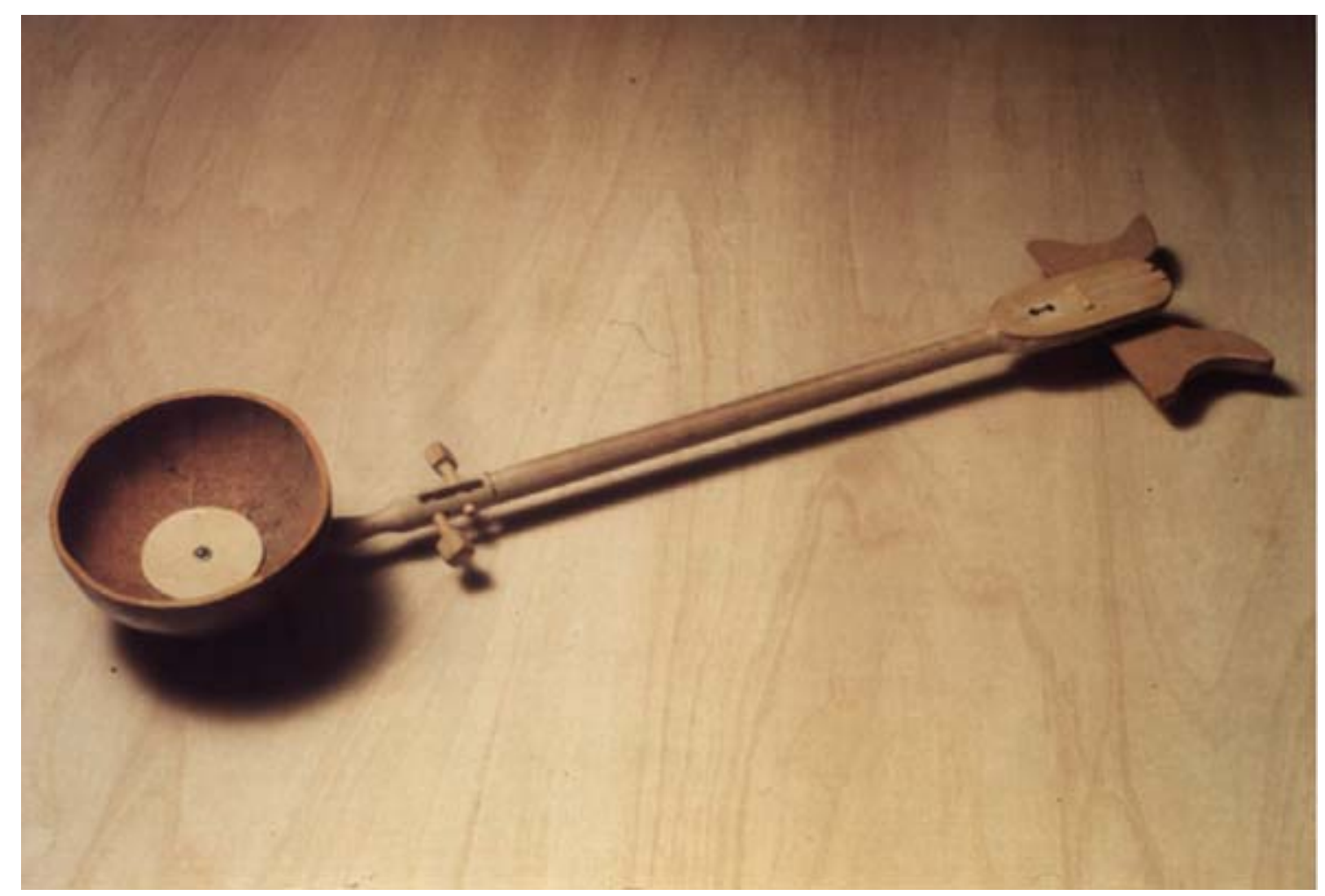

(C) 1994 Cristiano Quintino - FLOR

Estudos AvanÇADOS 14 (39), 2000 


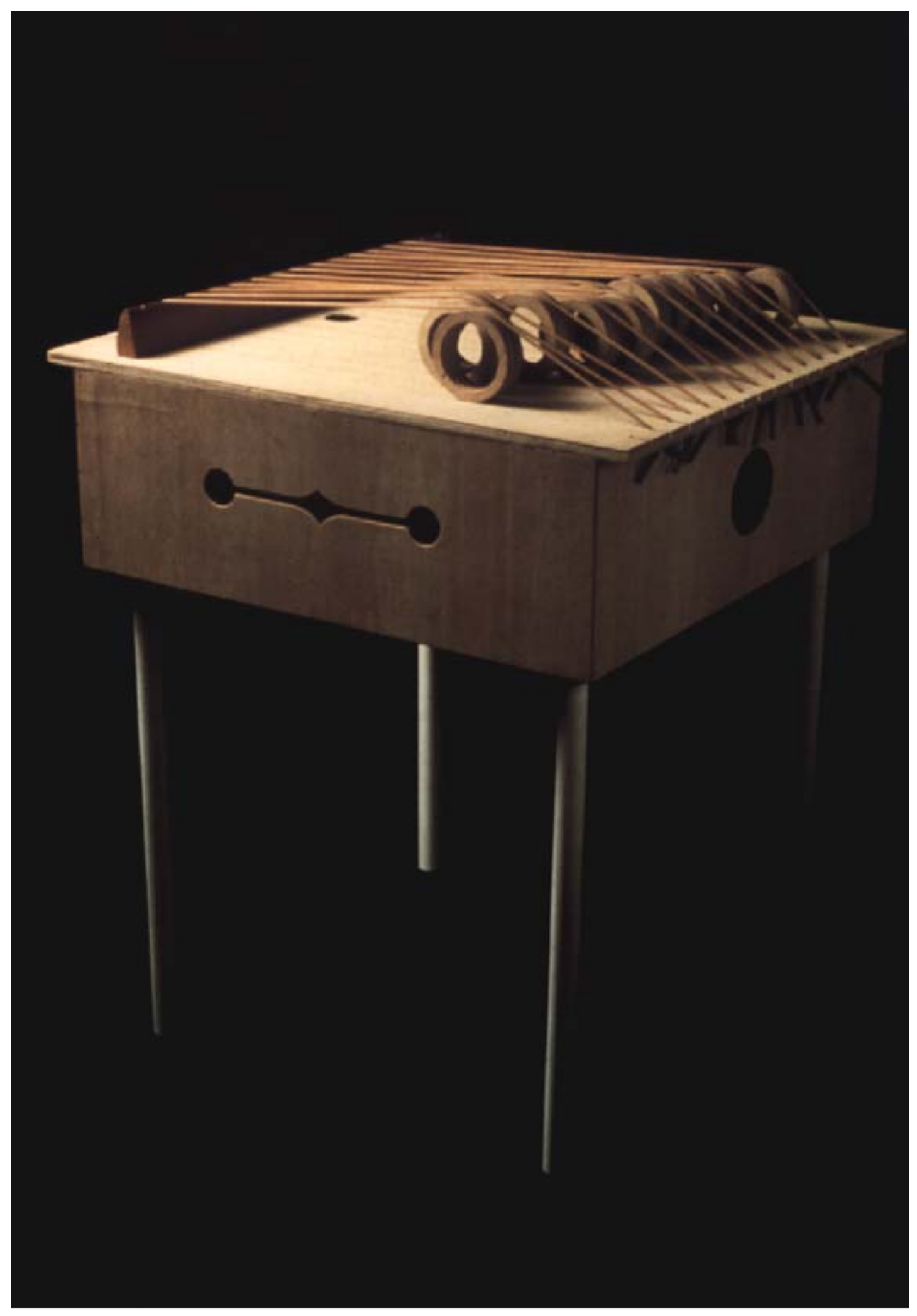

(C) 1994 Cristiano Quintino - PLANETÁRIO 


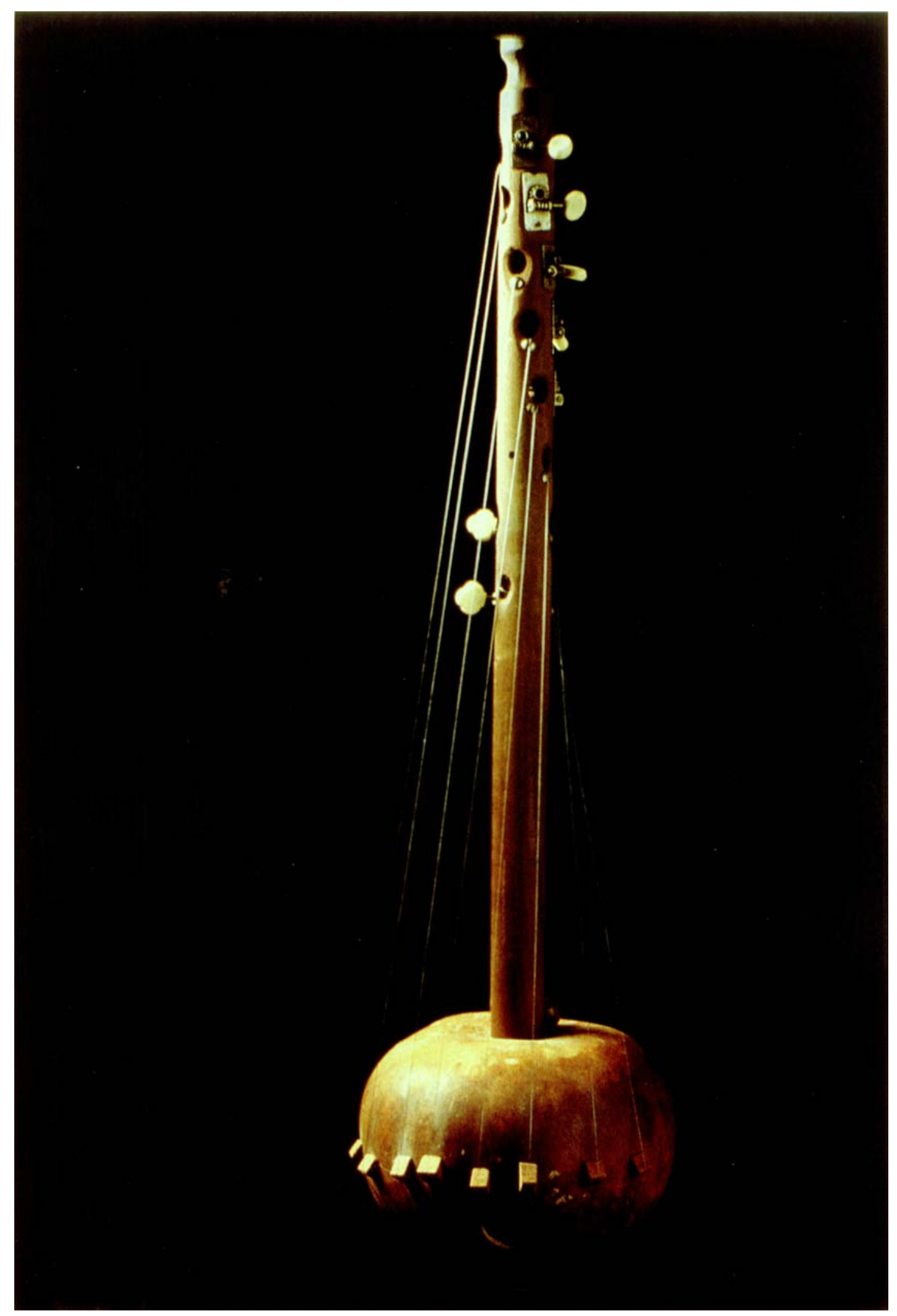

(C) 1994 Cristiano Quintino - $G I G$ 


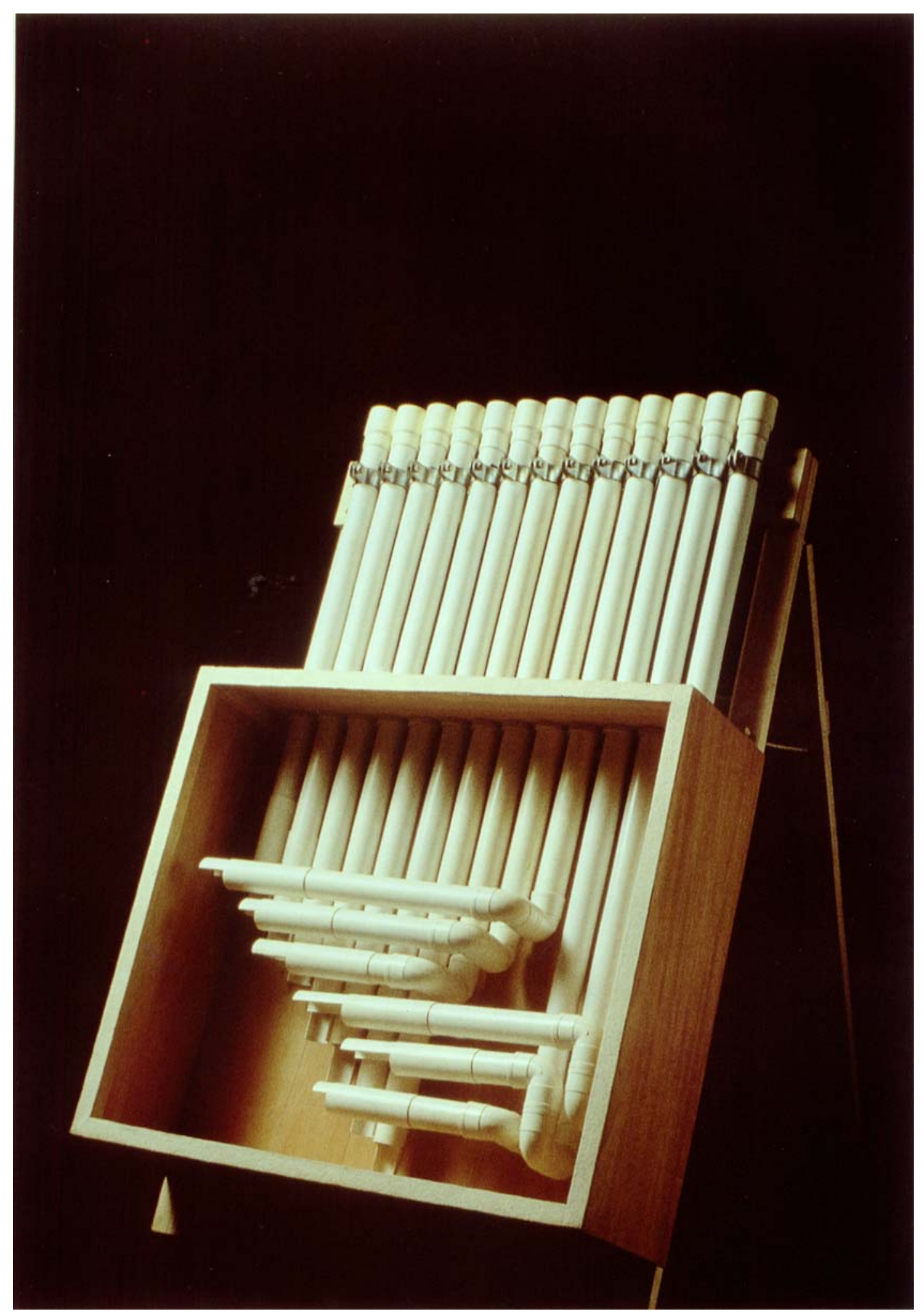

C 1994 Cristiano Quintino - PAN INCLINADO 


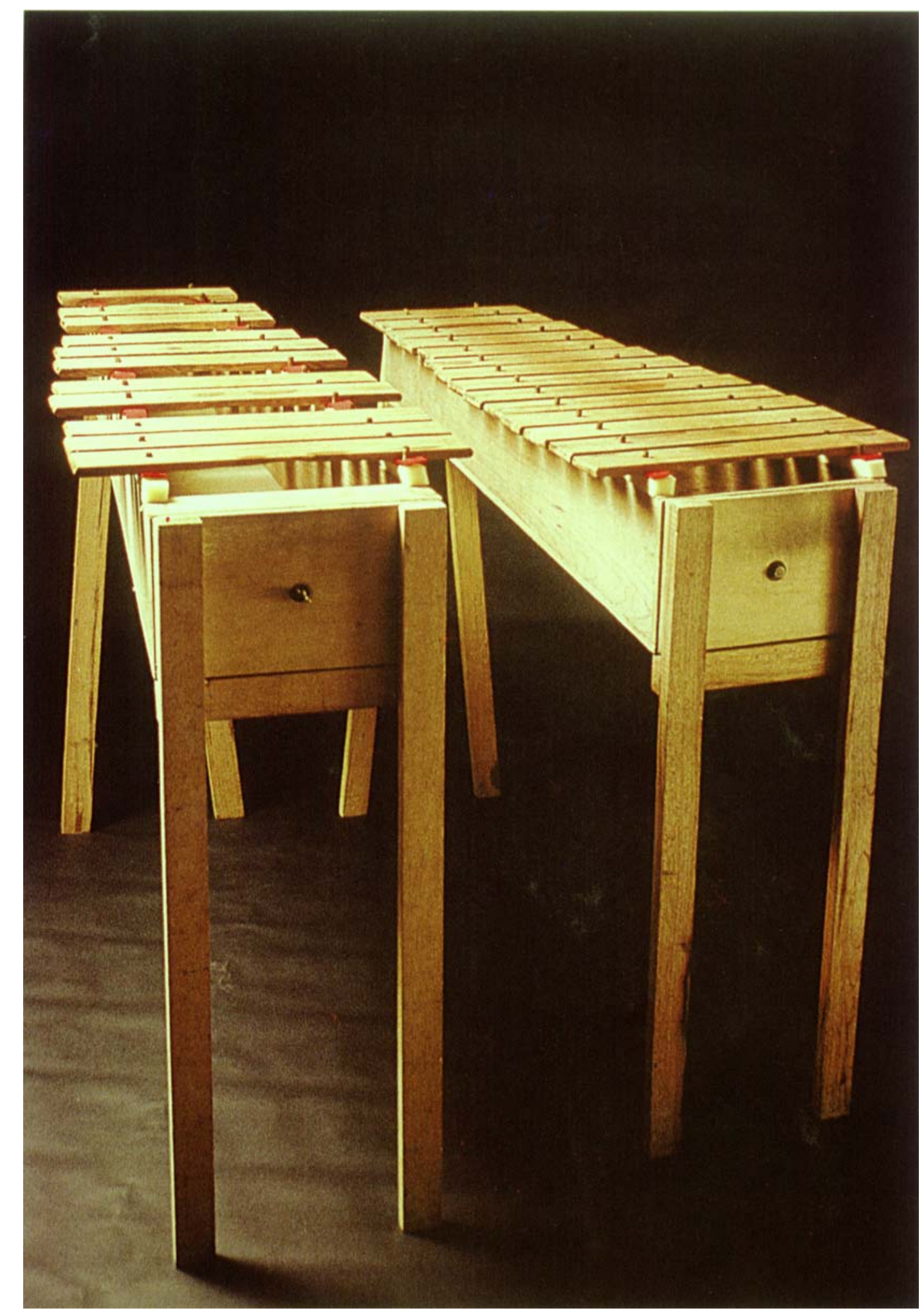

(C) 1994 Cristiano Quintino - MARIMBA D'ANGELIM 


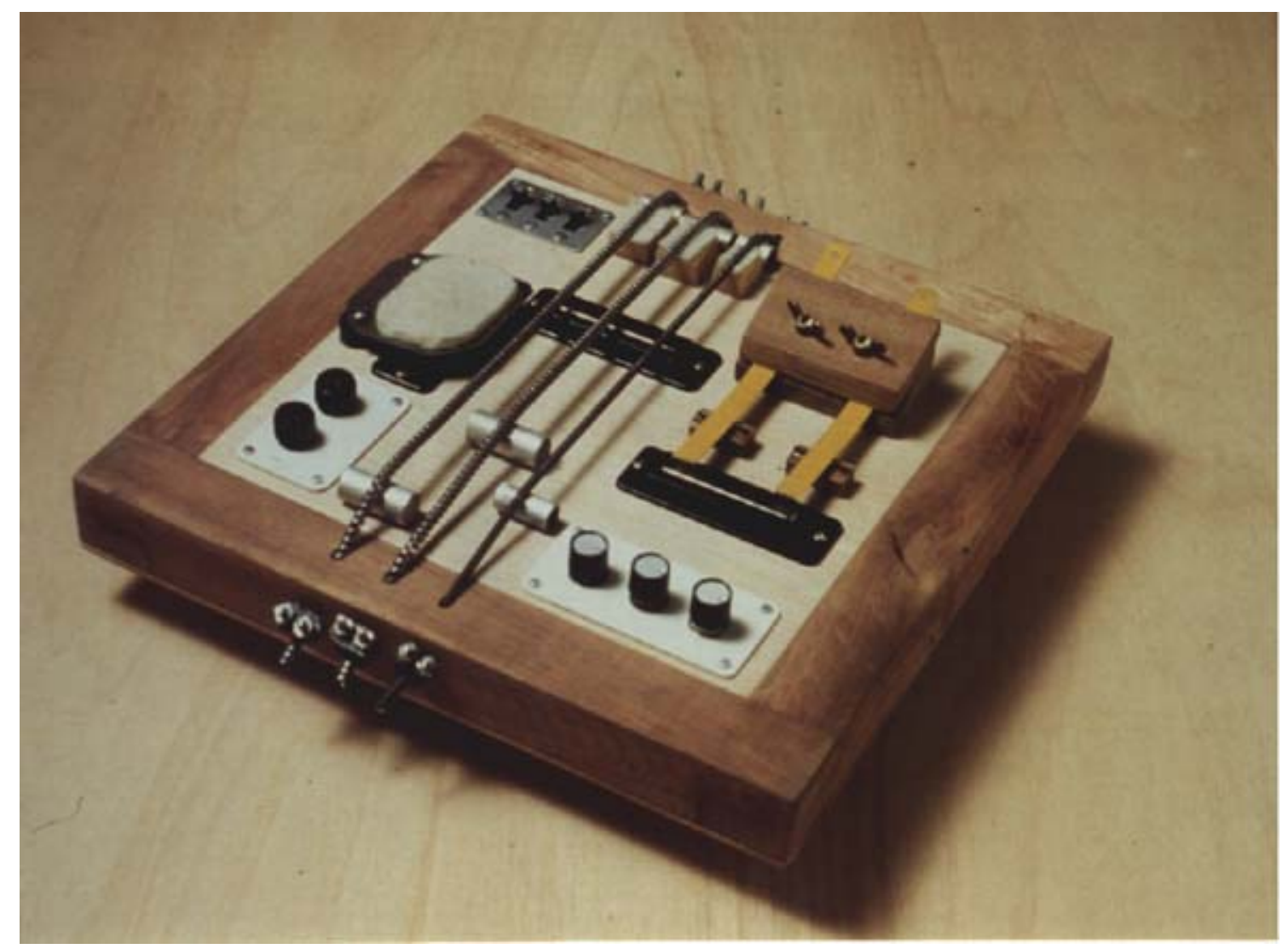

(C) 1994 Cristiano Quintino - TABLA ELÉTRICA

Discografia

Os nove discos lançados pelo grupo UAKTI são:

- Águas da Amazônia. Nova Iorque, EUA, Point-Music, 1999;

- Trilobyte. Nova Iorque, EUA, Point-Music, 1997;

- 21. São Paulo, Brasil, Paradoxx, 1997;

- I Ching. Nova Iorque, EUA, Point-Music, 1994;

- Mapa. Nova Iorque, EUA, Point-Music, 1992;

- Uakti. Nova Iorque, EUA, Verve, PolyGram, 1987;

- Tudo e todas as coisas. Rio de Janeiro, Brasil, PolyGram, 1984;

- Uakti II. Rio de Janeiro, Brasil, Ariola-Barclay, 1982;

- Uakti-Oficina Instrumental. Rio de Janeiro, Brasil, Ariola, 1981. 